\title{
AN ARTIFICIAL NEURAL NETWORK BASED PREESTIMATION FILTER FOR BAD DATA DETECTION, IDENTIFICATION AND ELIMINATION IN STATE ESTIMATION
}

Mehmet UZUNOĞLU
Celal KOCATEPE

\author{
Yildız Technical University \\ Elec.- Electro. Fac. \\ Electrical Eng. Dep.
}

Recep YUMURTACI

80750 Beşiktaş/ ISTANBUL-TURKEY

\begin{abstract}
State estimators are vitally important in energy control centers. The measurements that come from control system are generally analysed by a state estimator. Since there can always be bad measurements in the system, estimated value and the true value of the state estimator can be far from each other. In this paper, by using an artificial neural network (ANN), a bad data detection, identification and then elimination preestimation filter is outlined.
\end{abstract}

\section{Introduction}

The electrical energy, from generation to consumption, is measured, protected and controlled at various times. It is the control centers' job to obtain the safety and continuity of the electrical energy. For this, state estimators have an important role in energy control centers.

In control stations, measurement values are obtained by the SCADA system. This system is an application that collects the data needed for operators and other applied programs in control center and sends their commands to stations. By using the measurement value that come from the SCADA system and other data, state estimation and state variables of the network (bus voltage and angles) can be detected.

Measurement values come from SCADA system may include many errors. These errors are because of analogous numerical translators measurement equipment, etc. An important job of the state estimation is to detect and identify the measurement errors. Measurement errors cause the data be far from the true values. To handle this problem, several bad data detection and identification methods have been developed and reported in the literature.

Most common state estimation techniques in industry are based on the weighted least squares (WLS) method. These state estimators usually repeated an estimation detectionelimination cycle until an acceptable result is obtained. WLS based estimators cannot effectively detect and identify interactive and conforming bad data.

In this paper, a back propagation artificial neural network based preestimation method for bad data detection, identification and elimination is presented.

\section{ANNs and Data Handling}

For a non-linear relation or a complex pattern between input and output values, ANN is a very powerful estimation method. In most ANN applications, for constructing non-linear transfer functions, usually "back-propagation technique" is used.

In this paper, a preestimation filter is designed as shown in Fig.1. This filter detects and identifies the gross errors in raw measurements before the state estimation. For any data, 
it is said "bad" if the difference between the measurement variables is larger then an identification threshold

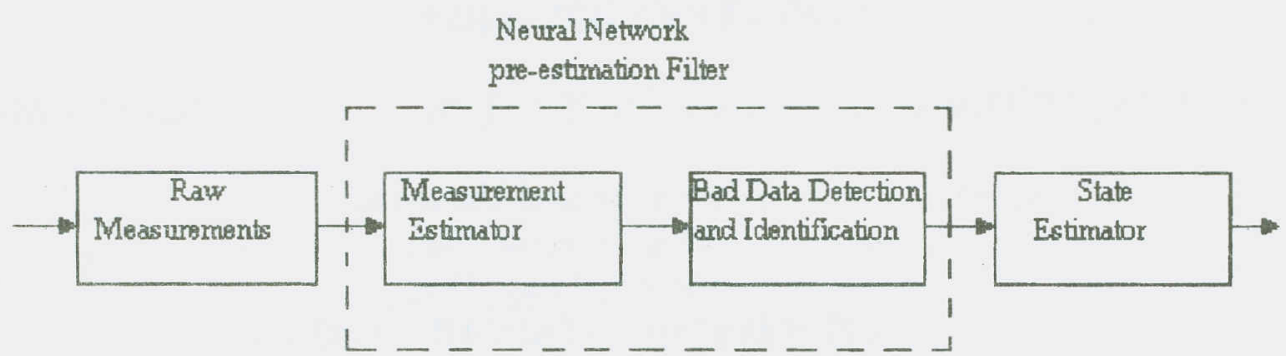

Figure 1. Preestimation Filter

During the training stage, the output part of a training pattern is the same as input part and both parts consist of correct measurements of the system. When the neural network is being trained, the connection weights are corrected to minimise the error between the true and estimated values of the measurement variables. In $\mathrm{ANN}$, the weights are the distributed associated memory units and show the current state of the knowledge. In training examples, systems operation measurements are shown with all weights and distributed among the measurements taken from system operation states. This will lead to a responsible network reasonable network response when the network is presented with incomplete, noisy or previously unseen inputs, and is referred to as "generalisation".

\section{Architecture of Proposed Measurement Estimator}

Architecture of a measurement estimator is composed of an input, an output and hidden layer as shown in Fig.2. The input values of the network are the measurements from a study system and these output units provide the input values estimated values.

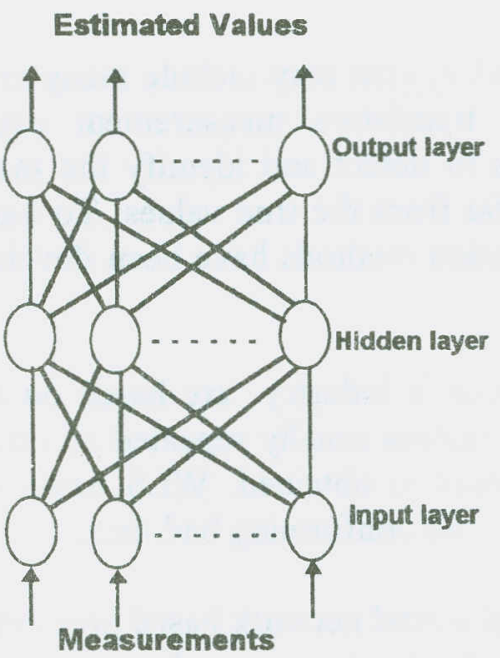

Figure 2. Architecture of the neural network measurement estimator

Given the true value of the measurement variable, the activation function developed for hidden and output layer is given by,

$\mathrm{O}_{\mathrm{i}}=\left[1-\exp \left(-\mathrm{g}_{\mathrm{i}}\right)\right] /\left[1+\exp \left(-\mathrm{g}_{\mathrm{i}}\right)\right]$ 
where $\mathrm{g}_{\mathrm{i}}$ and $\mathrm{O}_{\mathrm{i}}$ are the input and output for the ith unit respectively. This is a smooth version of a $(-1,1)$ step function. When the generalised delta rule is used as a training procedure, the error signal of the ith unit in the output layer is given by,

$\delta_{i}=(1 / 2) \cdot\left(1-\mathrm{O}_{\mathrm{i}}^{2}\right) \cdot\left(\mathrm{t}_{\mathrm{i}}-\mathrm{O}_{\mathrm{i}}\right)$

where $t_{i}$ is the desired output of the ith unit. The error signal of the ith unit in the hidden layer is given by,

$\delta_{\mathrm{i}}=(1 / 2) \cdot\left(1-\mathrm{O}_{\mathrm{i}}^{2}\right) \cdot \sum_{\mathrm{k}} \delta_{\mathrm{k}} \cdot \mathrm{W}_{\mathrm{ki}}$

where $\mathrm{k}$ is the unit index in the output layer and $\mathrm{W}_{\mathrm{k}}$ is the weight from ith to $\mathrm{kth}$ unit.

\section{Training Examples}

The true values of all training examples are obtained from power flow studies conducted over the entire system. The resultant measurements are divided into several measurement subsets each with an assigned neural network as in Fig.3. Many training patterns for each neural network are formed by selecting the true values of its corresponding measurement subset from the training examples. Each training pattern represents a training example for its corresponding neural network. Each neural network is actually trained to be an encoder, encoding its measurement subset onto itself. Such a trained network is called "associative". After training, each network becomes an estimator of a corresponding measurement subset.

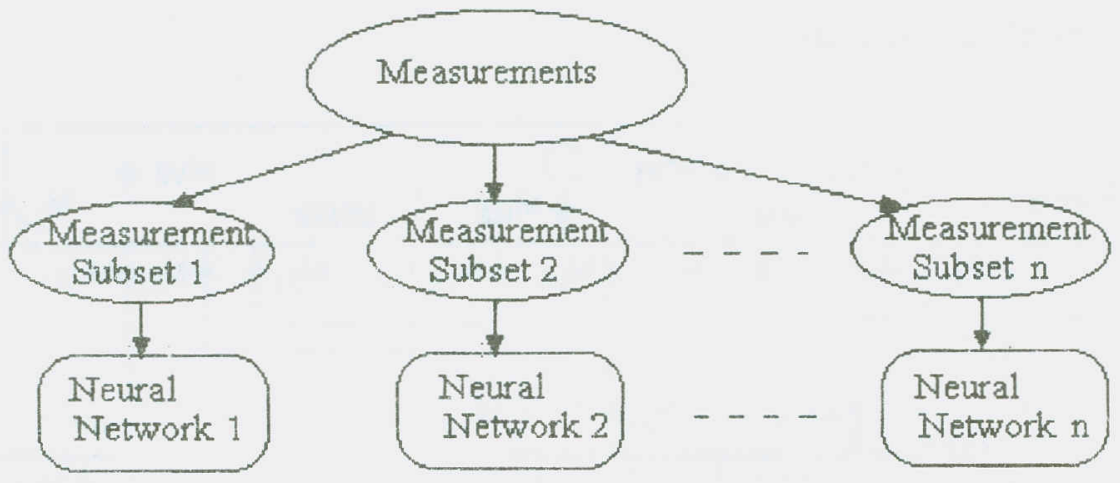

Fig.3. Measurements which are divided into several measurement subsets each with an assigned neural network

\section{Calculations with Bad Data}

In bad data detection and identification block of the filters comparison between measurement inputs and their estimated values flags the bad measurement inputs.

\subsection{Detection and identification of bad data}

If the difference of the bad data measurement and its estimated value is greater than the difference of a good measurement and its estimated value, bad measurement inputs are flagged. The rule for bad data detection and identification is as follows:

$\left(\mathrm{Z}_{\mathrm{i}}-\mathrm{O}_{\mathrm{i}}\right)^{2}>\mathrm{r}_{\mathrm{i}}^{2} \quad \mathrm{i}=1,2,3, \ldots, \mathrm{n}$ 
where, $Z_{i}$ is the measured value of the ith measurement variable, $O_{i}$ the estimated value of the ith measurement variable and $r_{i}$ the threshold value of bad data for the ith measurement.

According to this rule, if the square of the difference between the measured and estimated values of a measurement variable is greater than a given threshold, this value is flagged as bad measurement. The threshold of each variable is determined to be larger than its measurement standard deviation $\sigma_{I}$ and less than a critical error used in defining the bad data.

\subsection{Replacement of Bad Data}

With the proposed filter, bad measurement detection and replacement of bad measurement with good estimates can be provided. If there are too many bad measurements, detection and identification procedure can be repeated in order to get better estimations. The elimination of identified bad data cause locally or globally measurement system to make minimum number of calculations. A block diagram for detection bad data is given in figure 4 .

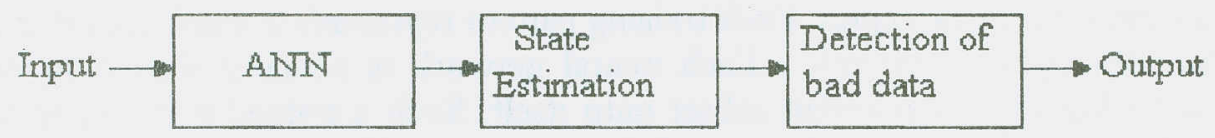

Figure 4. Block diagram for detection of bad data

\section{Numerical Application}

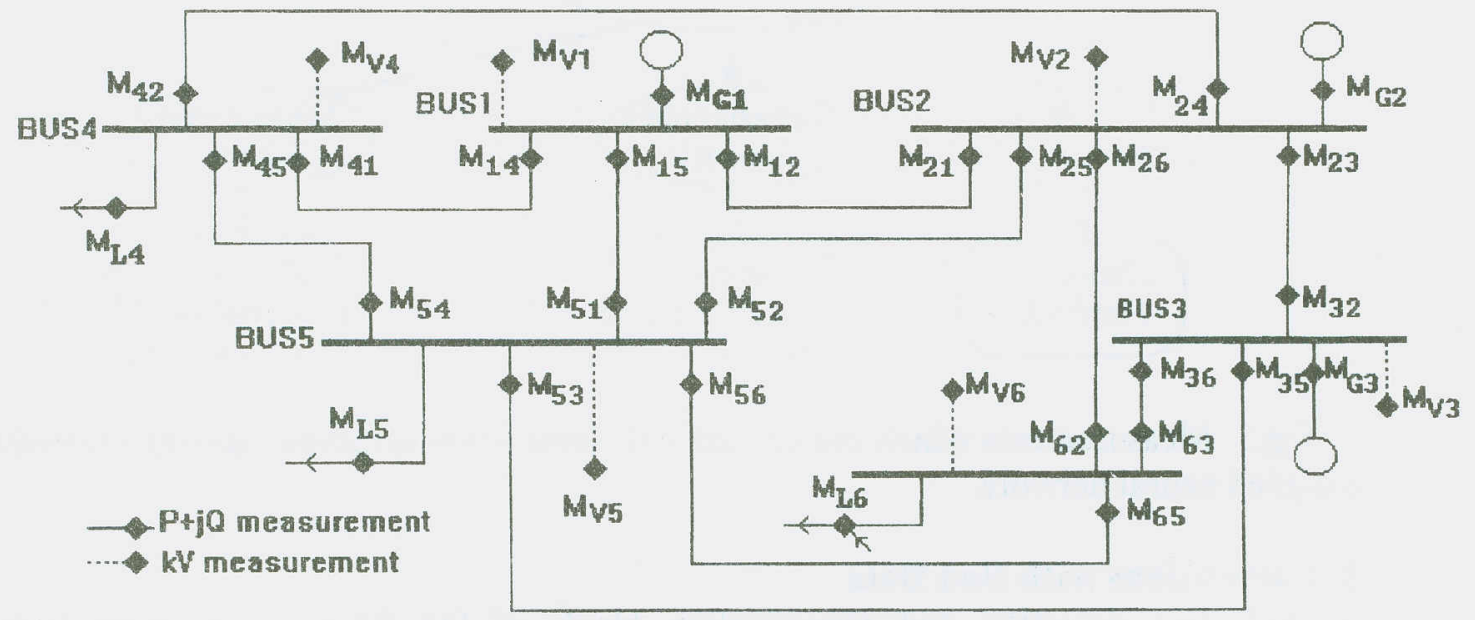

Figure 5. Example system for numerical application

In our study, as stated before, a back propagation ANN based bad data detection, identification and elimination method is applied on an example system as shown in Fig.5.

The characteristic values of the example system is given in Table 2 . The result of power flow analysis for the true values measurement value of the example system and the values when the procedure stated in our study is applied to the example system are shown in Table 1. 
TABLE 1. Values obtained from power flow (base case values), measured values and estimated values.

\begin{tabular}{|c|c|c|c|c|c|c|c|c|c|}
\hline \multirow[b]{2}{*}{ Measurement } & \multicolumn{3}{|c|}{$\begin{array}{l}\text { Base case value } \\
\quad \mathrm{g}_{\mathrm{i}}\end{array}$} & \multicolumn{3}{|c|}{$\begin{array}{l}\text { Measured value } \\
\qquad Z_{i}\end{array}$} & \multicolumn{3}{|c|}{$\begin{array}{c}\text { Estimated value } \\
\qquad \mathrm{O}_{\mathrm{i}}\end{array}$} \\
\hline & $\mathrm{t} \mathrm{kV}$ & MW & MVAR & $\mathrm{kV}$ & MW & MVAR & $\mathrm{kV}$ & $\mathrm{MW}$ & MVAR \\
\hline $\mathrm{M}_{\mathrm{V} 1}$ & 241.5 & & & 238.4 & & & 241.711 & & \\
\hline $\mathrm{M}_{\mathrm{Gl}}$ & & 107.9 & 16.0 & & 113.1 & 20.2 & & 107.9 & 15.999 \\
\hline $\mathrm{M}_{12}$ & & 28.7 & -15.4 & & -31.5 & 13.2 & & 28.699 & -15.399 \\
\hline $\mathrm{M}_{14}$ & & 43.6 & 20.1 & & 38.9 & 21.2 & & 43.6 & 20.1 \\
\hline $\mathrm{M}_{15}$ & & 35.6 & 11.3 & & 35.7 & 9.4 & & 35.599 & 11.299 \\
\hline $\mathrm{M}_{\mathrm{V} 2}$ & 241.5 & & & 237.8 & & & 241.742 & & \\
\hline $\mathrm{M}_{\mathrm{G} 2}$ & & 50.0 & 74.4 & & 48.4 & 71.9 & & 50.0 & 74.4 \\
\hline $\mathrm{M}_{21}$ & & -27.8 & 12.8 & & -34.9 & 9.7 & & -27.799 & 12.8 \\
\hline $\mathrm{M}_{24}$ & & 33.1 & 46.1 & & 32.8 & 38.3 & & 33.099 & 46.1 \\
\hline $\mathrm{M}_{2.5}$ & & 15.5 & 15.4 & & 17.4 & 22.0 & & 15.499 & 15.399 \\
\hline $\mathrm{M}_{26}$ & & 26.2 & 12.4 & & 22.3 & 15.0 & & 26.199 & 12.4 \\
\hline $\mathrm{M}_{23}$ & & 2.9 & -12.3 & & 8.6 & -11.9 & & 3.043 & -12.299 \\
\hline $\mathrm{M}_{\mathrm{V} 3}$ & 246.3 & & & 250.7 & & & 246.307 & & \\
\hline $\mathrm{M}_{\mathrm{G} 3}$ & & 60.0 & 89.6 & & 55.1 & 90.6 & & 60.0 & 89.6 \\
\hline $\mathrm{M}_{32}$ & & -2.9 & 5.7 & & -2.1 & 10.2 & & -3.043 & 5.607 \\
\hline $\mathrm{M}_{35}$ & & 19.1 & 23.2 & & 17.7 & 23.9 & & 19.099 & 23.2 \\
\hline $\mathrm{M}_{36}$ & & 43.8 & 60.7 & & 43.3 & 58.3 & & 43.8 & 60.7 \\
\hline $\mathrm{Mv}_{\mathrm{V}}$ & 227.6 & & & 225.7 & & & 227.623 & & \\
\hline $\mathrm{M}_{\mathrm{IA}}$ & & 70.0 & 70.0 & & 71.8 & 71.9 & & 70.0 & 70.0 \\
\hline $\mathrm{M}_{41}$ & & -42.5 & -19.9 & & -40.1 & -14.3 & & -42.5 & -19.9 \\
\hline $\mathrm{M}_{12}$ & & -31.6 & -45.1 & & -29.8 & -44.3 & & -31.599 & -45.1 \\
\hline $\mathrm{M}_{45}$ & & 4.1 & -4.9 & & 0.7 & -17.4 & & 4.123 & -4.902 \\
\hline Mvs & 226.7 & & & 225.7 & & & 226.347 & & \\
\hline$M_{L 5}$ & & 70.0 & 70.0 & & 72.0 & 67.7 & & 70.0 & 70.0 \\
\hline $\mathrm{M}_{54}$ & & -4.0 & -2.8 & & -2.1 & -1.5 & & -4.027 & -2.9204 \\
\hline $\mathrm{M}_{31}$ & & -34.5 & -13.5 & & -36.6 & -17.5 & & -34.499 & -13.5 \\
\hline $\mathrm{M}_{52}$ & & -15.0 & -18.0 & & -11.7 & -22.2 & & -14.999 & -18.0 \\
\hline $\mathrm{M}_{53}$ & & -18.0 & -26.1 & & -25.1 & -29.9 & & -17.999 & -26.1 \\
\hline $\mathrm{M}_{56}$ & & 1.6 & -9.7 & & -2.1 & -0.8 & & 2.132 & -9.699 \\
\hline $\mathrm{M}_{\mathrm{V} 6}$ & 231.0 & & & 228.9 & & & 230.957 & & \\
\hline $\mathrm{M}_{\mathrm{L} .6}$ & & 70.0 & 70.0 & & 72.3 & 60.9 & & 70.0 & 70.0 \\
\hline $\mathrm{M}_{69}$ & & -1.6 & 3.9 & & 1.0 & 2.9 & & -2.132 & 3.9174 \\
\hline $\mathrm{M}_{62}$ & & -25.7 & -16.0 & & -19.6 & -22.3 & & -25.169 & -16.0 \\
\hline $\mathrm{M}_{63}$ & & -42.8 & -57.9 & & -46.8 & -51.1 & & -42.8 & -57.9 \\
\hline
\end{tabular}

TABLE 2. Characteristic values of the example system

\begin{tabular}{|c|c|c|c|c|c|}
\hline \multicolumn{6}{|c|}{ BUS DATA } \\
\hline \multicolumn{2}{|c|}{ BUS NO. } & $\begin{array}{l}\text { GEN } \\
\text { ( pu MW ) }\end{array}$ & $\begin{array}{l}\text { VOLTAGE } \\
\text { (puKV) }\end{array}$ & $\begin{array}{l}\text { P LOAD } \\
\text { ( pu MW ) }\end{array}$ & $\begin{array}{l}\text { Q LOAD } \\
\text { ( pu MVAR) }\end{array}$ \\
\hline SWING & 1 & 0.00 & 1.050 & 0.00 & 0.00 \\
\hline & 2 & 0.50 & 1.050 & 0.00 & 0.00 \\
\hline & 3 & 0.60 & 1.070 & 0.00 & 0.00 \\
\hline & 4 & 0.00 & 1.000 & 0.70 & 0.70 \\
\hline & 5 & 0.00 & 1.000 & 0.70 & 0.70 \\
\hline & 6 & 0.00 & 1.000 & 0.70 & 0.70 \\
\hline
\end{tabular}




\begin{tabular}{ccccc}
\multicolumn{5}{c}{ LINE DATA } \\
FROM & TO & R & X & BCAP* \\
1 & 2 & 0.1000 & 0.2000 & 0.0200 \\
1 & 4 & 0.0500 & 0.2000 & 0.0200 \\
1 & 5 & 0.0800 & 0.3000 & 0.0300 \\
2 & 3 & 0.0500 & 0.2500 & 0.0300 \\
2 & 4 & 0.0500 & 0.1000 & 0.0100 \\
2 & 5 & 0.1000 & 0.3000 & 0.0200 \\
2 & 6 & 0.0700 & 0.2000 & 0.0250 \\
3 & 5 & 0.1200 & 0.2600 & 0.0250 \\
3 & 6 & 0.0200 & 0.1000 & 0.0100 \\
4 & 5 & 0.2000 & 0.4000 & 0.0400 \\
5 & 6 & 0.1000 & 0.3000 & 0.0300 \\
BCAP* = $1 / 2$ Total line charging
\end{tabular}

\section{Conclusion}

ANN based bad detection, identification and elimination procedure generally has great accuracy as shown in the numerical application made on the example system. When the result in Table 1 is examined, it seen that this system is superior and more economic (according to the cost comes from the computer speed) than other methods. Decreasing of error level depends on number of analysis in this method. We can say that number of analysis must be increased for minimum error level.

We decided that measurement values which are valid for Eq.4 are bad data in this numerical application. In this case, bad data are in the $\mathbf{M}_{12}(P, Q), \mathbf{M}_{21}(P), M_{24}(Q)$, $\mathrm{M}_{45}(\mathrm{Q}), \mathbf{M}_{53}(\mathrm{P}), \mathrm{M}_{56}(\mathrm{Q}), \mathrm{M}_{\mathrm{L} 6}(\mathrm{Q})$ measurement.

\section{References}

[1] F.C. Schweppe, J. Wildes and Rom, Power system static state estimation, Parts I,II,III, IEEE Trans. Power Appar. Syst., PAS-89 (1970) 120-135

[2] E. Handschin, F.C. Schweppe, Ji Kohlas and A. Fiechter, Bad data analysis for power system state estimation, IEEE Trans. Power Appar. Syst., PAS -94 (1975) 329-337

[3] H.M. Merril and F.C. Schweppe, Bad data suppression in power system static estimation, IEEE Trans. Power Appar. Syst., PAS -90 (1975) 2718-2725

[4] A. Garcia, A. Monticelli and P. Abreu, Fast decoupled state estimation and bad data processing, IEEE Trans. Power Appar. Syst., PAS -98 (1979) 1645-1652

[5] W. W. Kotiuga and M. Vidyasagar, Bad data rejection properties of weighed least absolute value techniques applied to static state estimation, , IEEE Trans. Power Appar. Syst., PAS 101 (1982) 844-851

[6] Xiang Nian-de, Wang Shi-ying and Yu Er-keng, A new aproach for detection and identification of multiple bad data in power system state estimation, IEEE Trans. Power Appar. Syst., PAS 101 (1982) 454-461

[7] A. J. Wood, B. F. Wollenberg, "Power Generation, Operation and Control", John Wiley and Sons (1984)

[8] G. N. Korres and G. C. Contaxis, A reduced model for bad data processing in state estimation, IEEE Trans. Power Syst., 6 (2) (1991) 550-556

[9] S. Weerasooriya, M. A. El-Sharkawi, M. Damborg and R. J. Marks, Towards static-security assesment of a large-scale power system using neural networks, IEE Proc. C. 139 (1992) 64-70 